\title{
KONFLIK BATIN TOKOH KIBITSUJI MUZAN DALAM MANGA KIMETSU NO YAIBA
}

\author{
T. Meizora ${ }^{1}$, N.V. Radoti ${ }^{2}$, Wulandari $^{3}$ \\ ${ }^{123}$ Jurusan Bahasa Asing, Universitas Pendidikan Ganesha, Singaraja \\ e-mail: tiara.meizora@undiksha.ac.id, nathania@undiksha.ac.id, wulandari.2@undiksha.ac.id
}

\begin{abstract}
Abstrak
Penelitian ini bertujuan untuk mendeskripsikan konflik batin pada tokoh antagonis yang bernama Kibutsuji Muzan dalam manga berjudul Kimetsu No Yaiba. Penelitian ini menggunakan metode deskriptif dan studi pustaka. Penelitian ini menggunakan pendekatan teori psikoanalisis sigmund freud yang meliputi id, ego, dan super ego. Hasil penelitian menunjukkan bentuk konflik batin yang dialami tokoh Kibutsuji Muzan dan faktor yang menjadi penyebab terjadinya konflik batin tersebut. Adapun konflik batin yang dialami tokoh Kibutsuji Muzan yaitu konflik batin tokoh Kibutsuji Muzan terkait kenyataan yang tidak selaras dengan harapannya; kebimbangan akan tujuan hidupnya yang sebenarnya, kebimbangan akan menolak atau menerima pertanyaan yang sangat sesuai dengan realita, kebimbangan dalam mengambil sebuah keputusan besar pada situasi mendesak di akhir kehidupannya. Dan faktor yang mempengaruhi munculnya konflik batin dalam diri Muzan adalah pertentangan yang terjadi anatar id, ego, dan super ego, serta lemahnya peran super ego dalam diri Kibutsuji Muzan.
\end{abstract}

Kata kunci: konflik batin, manga, psikoanalisis, Sigmund Freud.

\begin{abstract}
This study aims to describe the inner conflict of an antagonist named Kibutsuji Muzan in Kimetsu No Yaiba manga. This research used descriptive method and literature study and uses the approach of Sigmund Freud's psychoanalytic theory which includes id, ego, and super ego. The results showed the form of inner conflict experienced by the character Kibutsuji Muzan and the factors causing the inner conflict. As for the inner conflict experienced by the character Kibutsuji Muzan are as follows: the inner conflict of the character Kibutsuji Muzan related to the reality that is not in line with his expectations, doubt about the true purpose of his life, doubt about rejecting or accepting a statement that is very true to reality, hesitation in making a big decision in an urgent situation at the end of his life. And the factors that influence the emergence of inner conflict within Muzan are the conflicts that occur between the id, ego, and super ego, as well as the weak role of the super ego that is in Kibutsuji Muzan.
\end{abstract}

Keywords: inner conflict, manga, psychoanalysis, Sigmund Freud.

\section{Pendahuluan}

Manga Kimetsu no Yaiba adalah sebuah manga terbitan majalah Weekly Shounen Jump oleh seorang mangaka bernama Gotouge Koyoharu. Manga ini menceritakan tentang seorang pemuda bernama Tanjiro Kamado, ia merupakan pemuda sulung yang berasal dari keluarga yang kurang mampu dan tinggal di pedalaman gunung pada era Taisho. Sejak dahulu kala rumor mengenai Oni (Iblis pemakan manusia) yang bersembunyi di hutan diketahui oleh penduduk setempat, hal tersebut membuat penduduk ketakutan dan enggan keluar di malam hari. Namun, hal tersebut tidak diperdulikan oleh Tanjiro dan menganggap hal tersebut hanya sekedar rumor belaka. Meskipun ia hidup dalam keluarga yang kurang mampu dan dia harus menjadi tulang punggung keluarga sejak kematian ayahnya, ia masih bisa merasakan kebahagiaan serta kehangatan dari keluarganya. Namun, kebahagiaan tersebut seketika hilang saat Tanjiro melihat keluarganya dibantai, dan satu-satunya yang selamat hanya adik perempuannya Nezuko, berubah menjadi Oni. Hal tersebut membuat Tanjiro memutuskan untuk menjadi pemburu iblis untuk menolong adiknya agar dapat kembali menjadi manusia seperti sebelumnya. 
Muzan adalah tokoh antagonis dalam manga Kimetsu no Yaiba. la adalah Oni pertama yang lahir dari hasil obat Blue Spider Lily dan berhasil mengubah Nezuko menjadi seorang iblis. Sebelum menjadi iblis, muzan merupakan seorang manusia namun pada saat itu ia menderita penyakit yang sangat berbahaya dan mengancam nyawanya. Muzan mengalami frustasi dan meyakini bahwa perawatan yang dilakukan hanya sia-sia dan hanya membuatnya semakin menderita. Sebelumnya, Muzan telah diberikan obat Blue Spider Lily oleh dokter, namun setelah mengetahui efek samping yang akan dirasakan Muzan yaitu tidak dapat terkena sinar matahari, Muzan marah besar akibatnya ia tega membunuh dokter yang membantunya untuk sembuh. Agar keinginannya dapat terwujud yaitu memiliki tubuh yang tahan sinar matahari, ia harus mengonsumsi Blue Spider Lily yang sudah sangat susah untuk ditemukan. Hal tersebut membuat ia melakukan segala macam cara seperti menciptakan iblis dengan darahnya agar iblis yang ia ciptakan dapat membantunya untuk menemukan obat tersebut.

Kejahatan yang dilakukan oleh tokoh Muzan dimulai dari rasa frustasinya yang harus merelakan kemanusiaannya dan menjadi seorang iblis. Mengetahui fakta bahwa ia tidak dapat mengekspos dirinya ke sinar matahari membuat ia semakin merasa putus asa akan kenyataan tersebut. Keinginanya yang ingin memiliki tubuh yang kuat dan tahan sinar matahari yang membuatnya menghalalkan segala cara agar tujuannya tercapai, meskipun cara yang ia lakukan sangat merugikan banyak orang terutama tokoh Tanjiro yang mengalami penderitaan setelah mengetahui adik perempuannya telah berubah menjadi iblis.

Hal yang menarik perhatian kami terhadap tokoh muzan yaitu kejahatan dan tindakan keji yang ia lakukan sangat menonjol, rasa egois pada dirinya sehingga hanya memperdulikan dirinya sendiri, dan kami merasa bahwa dari semua tindakan keji yang dilakukan oleh Muzan terdapat sebab mengapa tokoh muzan melakukan hal tersebut. Maka dari itu, dari ketertarikan kami terhadap tokoh Muzan, kami sangat ingin menganalisis lebih lanjut tokoh tersebut.

Agar penelitian yang dilakukan terarah dan mendapatkan hasil yang diharapkan, maka harus ditetapkan rumusan masalah. Adapun rumusan masalah pada penelitian ini adalah bagaimana konflik batin tokoh Muzan pada manga Kimetsu no Yaiba.

Dengan ditentukannya rumusan masalah maka dapat diketahui tujuan dari penelitian, yaitu untuk mendeskripsikan konflik batin tokoh Muzan dalam manga Kimetsu no yaiba.

Menurut Kamus Besar Bahasa Indonesia (KBBI), konflik batin adalah konflik yang disebabkan oleh adanya gua gagasan atau atau lebih, atau keinginan yang saling bertentangan untuk menguasai diri sehingga mempengaruhi tingkah laku. Selain itu, adapun beberapa pendapat para ahli mengenai konflik batin. Seperti, menurut Afrianti (2012:196) menjelaskan bahwa konflik merupakan pertentangan dua keinginan untuk memenuhi kebutuhan dalam waktu bersamaan pada diri seseorang, sehingga memengaruhi tingkah laku. Berdasarkan bentuknya konflik dapat dibedakan menjadi dua, yakni konflik internal dan konflik eksternal.

Nurgiantoro (2013:181) menjelaskan bahwa konflik batin adalah konflik yang terjadi dalam hati dan pikiran sekaligus dalam jiwa seseorang. Konflik batin disebabkan adanya pertentangan antara keinginan, keyakinan, pilihan yang berbeda, harapan-harapan serta berbagai masalah lainnya.

Kemudian, menurut Sudigjo (2014:7) menjelaskan bahwa konflik batin merupakan tipe yang paling erat kaitannya dengan emosi individu. Konflik ini dapat muncul dari dua sebab, yakni karena merasa kelebihan beban dan ketidaksesuaian dalam melaksanakan peranan.

Adapun pandangan Ratna (2009:6263) terkait Teori Sigmund Freud apabila dikait dengan konflik batin, beliau menjelaskan bahwa konflik batin terjadi karena adanya pertentangan dengan id, ego, dan super ego pada suatu tokoh. Id berperan sebagai pemberi dorongan, ego merupakan pikiran yang rasional, dan super ego berperan sebagai pengendali yang berisi sistem nilai dan norma yang berlaku dikalangan masyarakat.

Berdasarkan beberapa pendapat menurut para ahli yang sudah dijabarkan diatas, dapat kami simpulkan bahwa konflik batin merupakan keadaan dimana suatu tokoh mengalami pertentangan pada dirinya sendiri, tentu hal ini bersifat tidak menyenangkan. 
Karena hal tersebut mengharuskan suatu tokoh berusaha untuk mencari solusi dari konflik yang dialaminya.

Pembahasan dan kegiatan analisis dalam penelitian ini menggunakan pendekatan teori Psikoanalisis Sigmund Freud. Sigmund Freud beramsumsi bahwa energi penggerak perilaku manusia berawal dari dalam diri manusia yang terletak di alam bawah sadar. Oleh karena itu ada banyak kejadian dimana penyakit fisik seseorang disebabkan karena tertekannya psikologis seseorang. Menurut Sigmund Freud jiwa manusia memiliki tiga tingkatan kesadaran, yaitu sadar, prasadar, dan tak sadar. Kesadaran hanyalah sebagian kecil dari kehidupan mental seseorang, sedangkan sebagian besarnya adalah ketidaksadaran.

Psikoanalisis menurut Sigmund Freud terdiri atas Id, Ego, dan Super Ego. Id adalah sistem kepribadian manusia yang paling mendasar yang dibawa sejak lahir dan berwujud insting, nafsu, atau kemauan manusia yang tidak mengenal nilai moral. Id bekerja berdasarkan berdasarkan prisip kenikmatan, yaitu berusaha memperoleh kenikmatan dan menghindari rasa sakit atau ketidaknyamanan. Id hanya bisa membayangkan sesuatu tanpa bisa membedakan antara khayalan dengan kenyataan yang benar-benar bisa memuaskan kebutuhan atau memenuhi kenikmatan. Ego berkembang dari ld agar mampu menangani realita. Ego bekerja memikirkan cara untuk mendapatkan objek nyata yang benar-benar dapat memenuhi kepuasan dari Id. Sehingga Ego juga bekerja di daerah kesadaran. Tugas Ego adalah menentukan tujuan atau memilih kenikmatan mana yang akan dipuaskan sesuai dengan prioritas kebutuhan, serta kapan dan bagaimana kebutuhan itu dipuaskan. Super Ego merupakan nilai-nilai moral yang mewakili nilai-nilai yang didapat dari ajaran orang tua, norma, budaya, agama, dan lain-lain tentang standar sosial. Super Ego dapat mendorong Ego untuk mengganti tujuan dan menghambat keinginan $I d$ yang bertentangan dengan nilai moral.

Adapun manfaat dari penelitian ini adalah diharapkan mampu menambah pengetahuan terkait psikologis, khususnya mengenai teori psikoanalisis yang dikemukakan oleh Sigmund Freud.

\section{Metode Penelitian}

Penelitian yang dilakukan berupa penelitian kualitatif, yaitu penelitian yang dilakukan untuk menganalisis dan menjelaskan suatu fenomena, peristiwa, dinamika sosial, sikap atau perilaku dan segala hal yang berhubungan untuk memahami tentang apa yang dialami oleh subjek penelitian.

Dalam mengumpulkan data kami menggunakan studi pustaka, yaitu membaca keseluruhan manga Kimetsu no Yaiba, lalu mengelompokan fenomena yang berkaitan dengan pokok permasalahan yang diangkat, kemudian menganalisa menggunakan teori Psikoanalisis Sigmund Freud. Kami juga menggunakan buku, makalah, hasil penelitian, dan tulisan-tulisan serta data-data dari internet yang revelan dengan pokok permasalahan yang diangkat.

Kami juga menggunakan metode deskriptif yang bertujuan mendeskripsikan gambaran fakta, sifat, serta hubungan antar fenomena yang diselidiki secara sistematis, faktual, dan akurat.

Adapun langkah-langkah yang kami lakukan dalam penelitian adalah membaca keseluruhan manga Kimetsu no Yaiba, dan mengumpulkan fenomena-fenomena atau datadata terkait tokoh Muzan di dalam manga yang akan dianalisis dan dideskripsikan dengan teori psikoanalisis Sigmund Freud. Data yang dikumpulkan adalah data verba berupa dialogdialog dan data visual yang berkaitan dengan tokoh Muzan di dalam manga Kimetsu no Yaiba. Kemudian kami juga mengumpulkan data-data dari jurnal, artikel, penelitianpenelitian, buku, serta data-data dari internet yang berkaitan dengan pokok permasalahan, sebagai referensi dan dasar berfikir atau kerangka teori dalam melakukan penelitian. 
Data-data yang telah dianalisis akan disusun dan dideskripsikan menjadi lebuah laporan. Penarikan kesimpulan kami lakukan dari awal pengumpulan data hingga data-data tersebut dianalisis.

\section{Hasil dan Pembahasan}

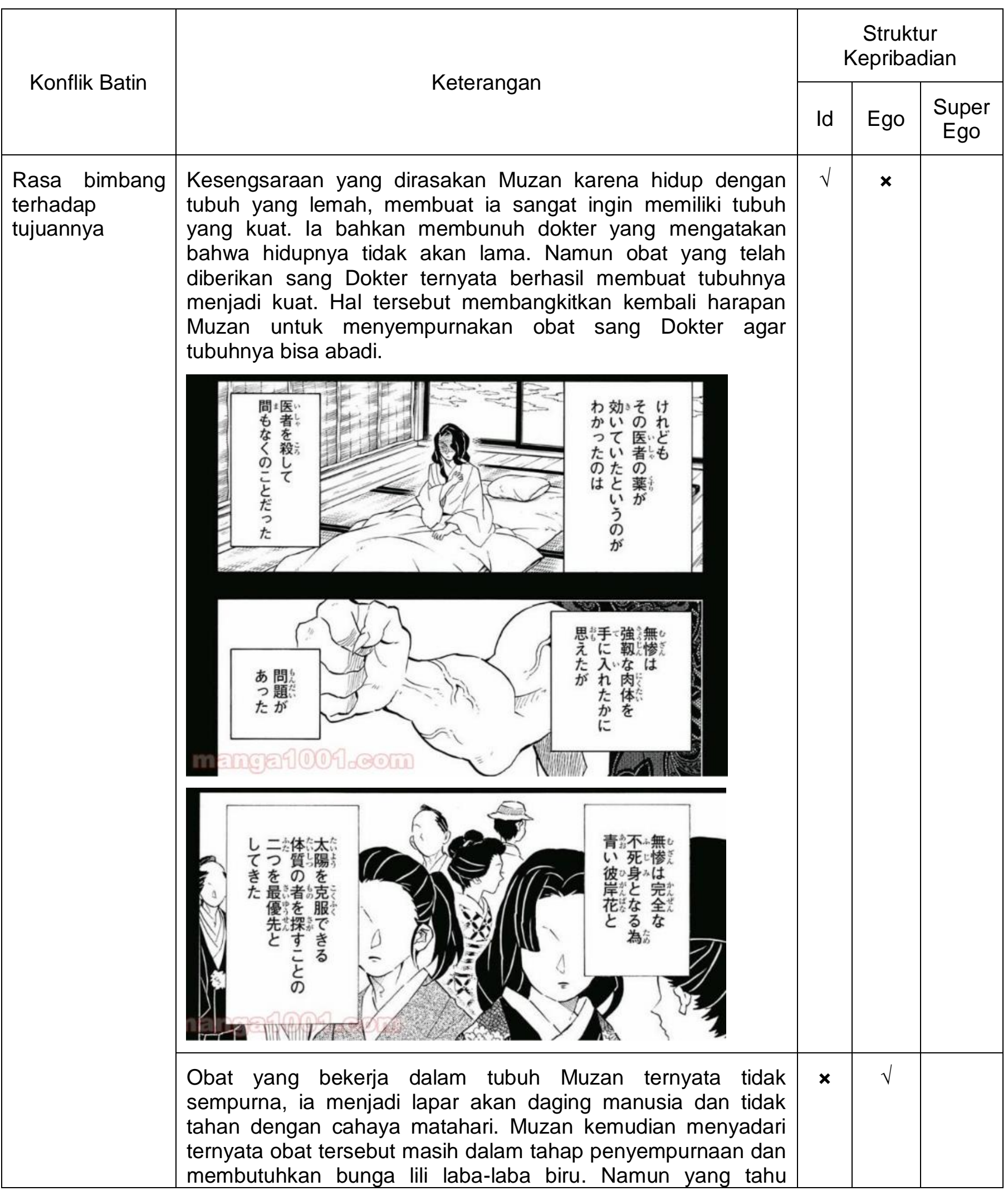




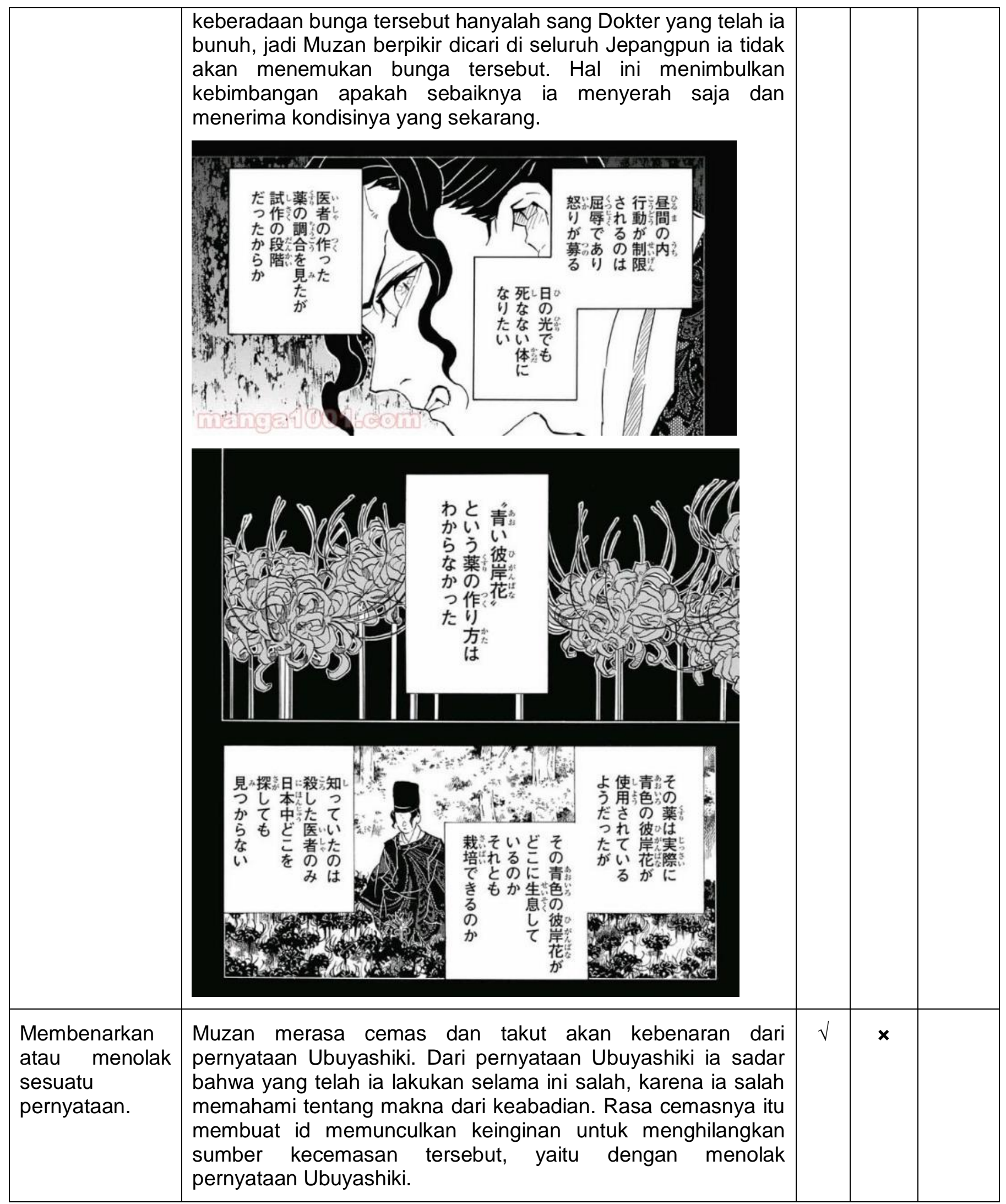




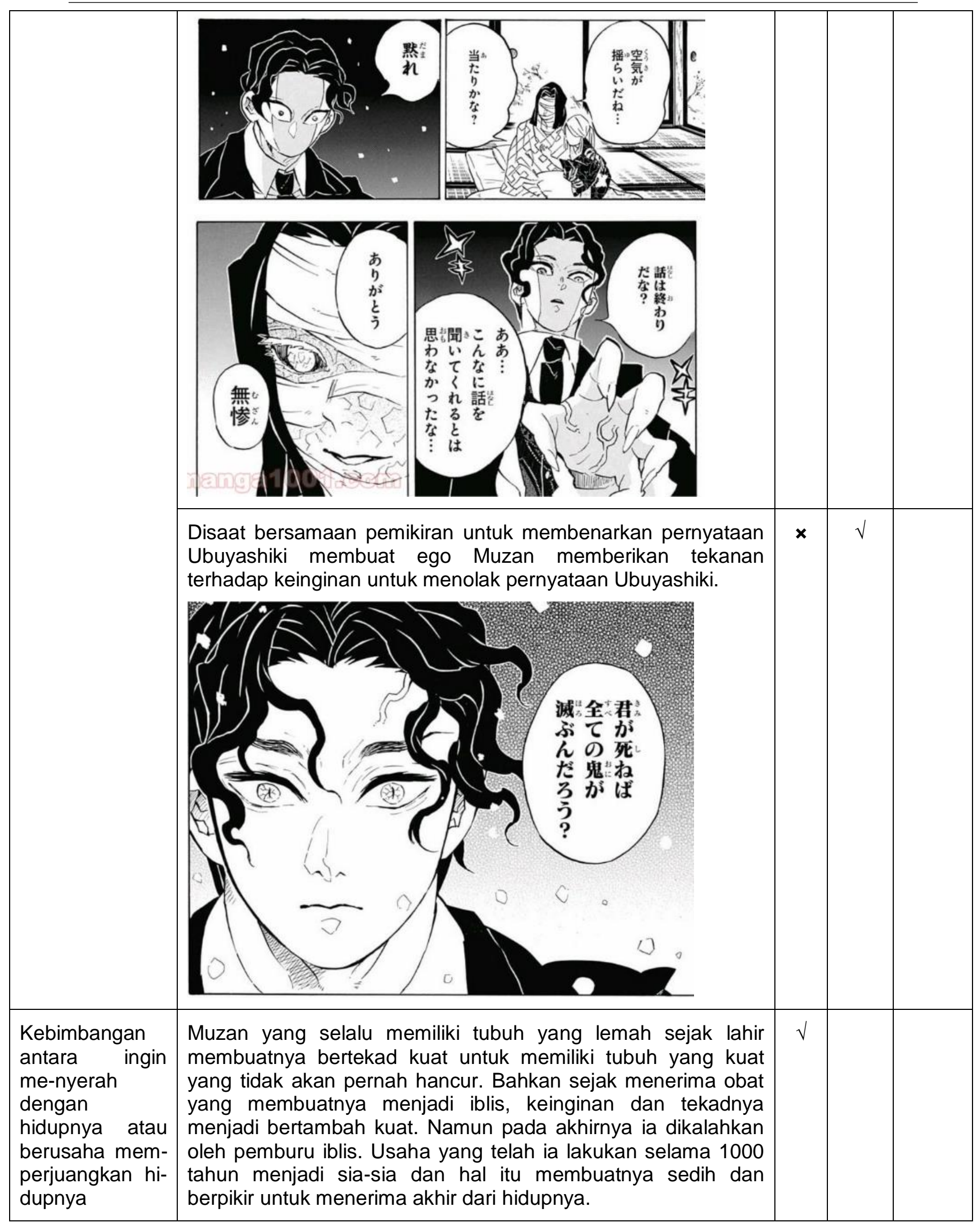



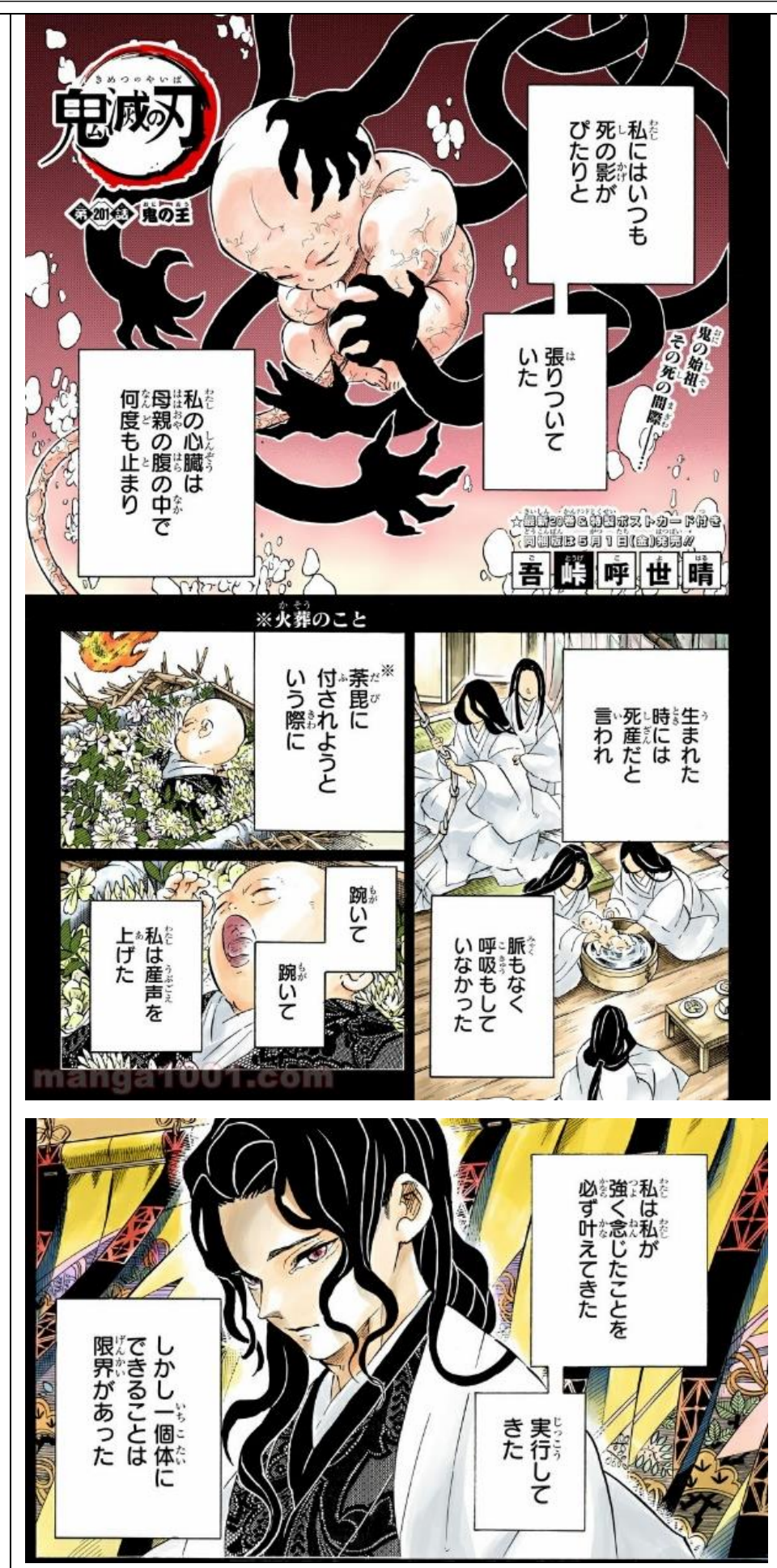

Dibalik tekanan situasi ketika ia akan terbakar sepenuhnya oleh matahari setelah dikalahkan oleh pemburu iblis, Muzan masih memiliki harapan untuk pikirannya terwariskan, sehingga ia masih memiliki keinginannya untuk menjadi makhluk yang kuat dan abadi. 


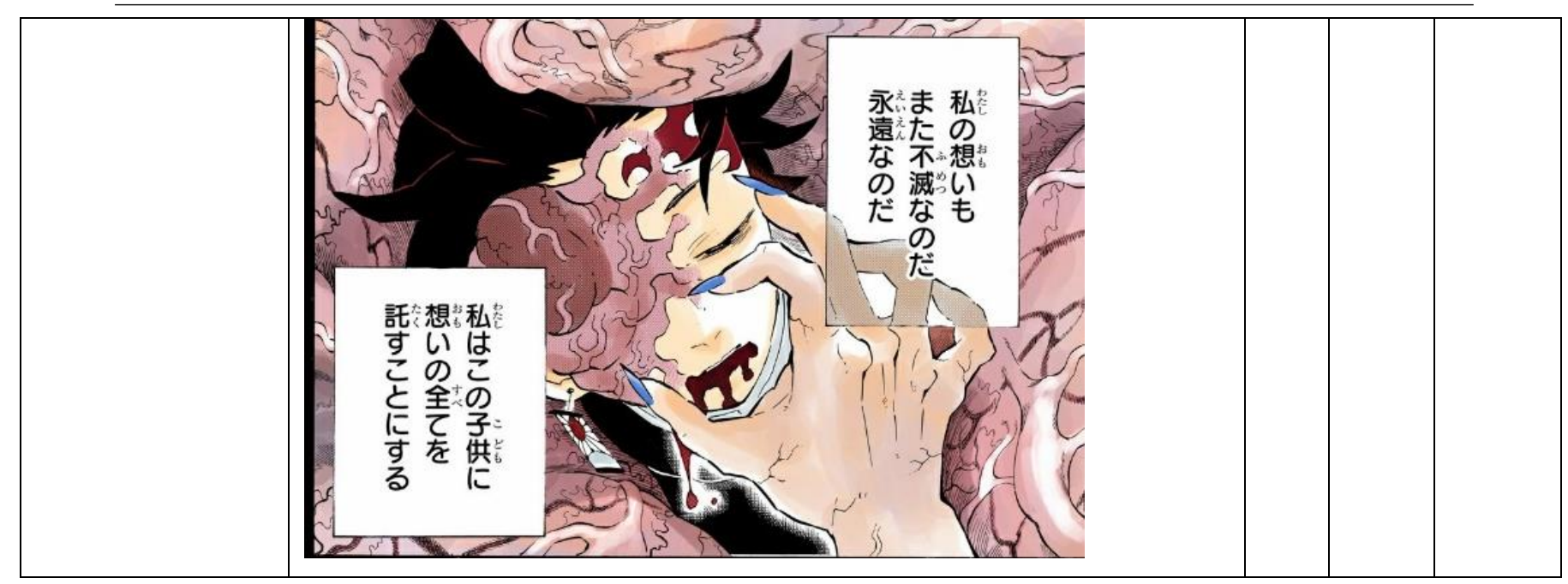

1) Konflik Batin Yang Dipicu Rasa Bimbang Muzan Terhadap Tujuannya

Di masa lalu ketika ia mulai memiliki tubuh yang kuat Muzan mengalami konflik batin. Pertentangan terjadi antara id dan ego, tepatnya antara energi pendorong dari id (kateksis) dengan energi-energi yang menekan keinginan id yang dimiliki ego (antikateksis). Pertentangan ini menyebabkan kebimbangan pada diri Muzan dalam memutuskan tujuannya.

Pada chapter 127, diceritakan Muzan memiliki tubuh lemah sejak lahir. la membunuh dokter yang berusaha menyembuhkannya, dikarenakan dokter tersebut mengatakan bahwa Muzan tidak akan berumur panjang karena tubuh lemahnya. Setelah kematian sang Dokter Muzan menyadari obat yang telah diberikan sang Dokter kepadanya bekerja dengan baik ditubuhnya. Namun obat tersebut tidak sepenuhnya membuat kondisi Muzan membaik. Muzan menjadi lapar akan daging manusia sehingga ia harus memakan manusia untuk mengatasi rasa laparnya. Efek lain dari obat yang diberikan juga membuatnya tidak bisa bertahan dibawah sinar matahari. Saat melihat bahan obat yang dibuat oleh sang dokter ia menyadari ternyata obat tersebut masih dalam percobaan, sehingga ia tidak tahu bagaimana cara membuat obat yang dinamakan "bunga lili laba-laba biru". Obat tersebut sepertinya memerlukan bunga lili laba-laba bewarna biru, namun yang tahu keberadaan bunga tersebut hanyalah dokter yang telah ia bunuh. Kesulitannya menemukan bunga tersebut membuat Muzan merasa bimbang dan memicu timbulnya konflik batin pada dirinya.

Diri Muzan dipengaruhi oleh keinginan terbesarnya yaitu ingin memiliki tubuh yang kuat dan sempurna yang dapat bertahan di bawah matahari. la benci dengan kenyataan bahwa ia hanya bisa bergerak disaat malam hari. Energi-energi pendorong (kateksis) yang dihasilkan id Muzan mendorongnya untuk berusaha mewujudkan keinginan tersebut. Namun kenyataan yang dilihat oleh ego, yaitu tidak diketahuinya keberadaan bunga lili laba-laba biru dan sulitnya membuat obat yang bisa menjadikan tubuh tahan dengan matahari, memunculkan tekanan-tekanan yang membuat Muzan untuk mengurungkan keinginannya, dan menerima keadaannya sekarang. Sehingga Muzan mengalami kebimbangan antara memilih untuk menyerah dan menerima keadaan tubuhnya yang sekarang, atau berusaha untuk membuat obat dari bunga lili laba-laba biru.

Akhirnya Muzan memilih untuk terus berusaha menemukan bunga lili laba-laba biru. la sangat menginginkan tubuh yang abadi dan sempurna. Namun, selama proses Muzan dalam mencari keberadaan bunga tersebut, ia terus mengalami kesulitan. Karena itu ia akan melakukan segala cara, baik tindakan keji sekalipun seperti memakan manusia, membunuh, mengubah manusia menjadi iblis, dan tindakan lainnya untuk bisa menemukan cara agar ia bisa bertahan di bawah sinar matahari. 
2) Konflik Batin Yang Dipicu Oleh Suatu Pernyataan

Konflik batin ini dialami Muzan ketika ia mendengar pernyataan dari Ubuyashiki Kagaya, pemimpin pasukan pemburu iblis. Mendengar pernyataan tersebut membuat Muzan mengalami koflik batin antara menerima atau menentangnya, yang menunjukkan adanya pertentangan antara id dengan ego.

Pada chapter 137, Ubuyashiki Kagaya menyatakan bahwa keinginan Muzan akan tubuh yang abadi dan tidak dapat hancur tidak akan menjadi kenyataan. Menurut Ubyashiki, Muzan salah dalam memahami tentang keabadian. Keabadian adalah perasaan manusia, perasaan yang tidak akan dapat dihancurkan oleh waktu meskipun manusia tersebut tela tiada. Perasaan tidak akan memaafkan Muzan yang telah merenggut nyawa orang berharga mereka membuat pasukan pemburu iblis tidak musnah selama ratusan tahun. Pasukan pemburu iblis akan selalu ada dan memburu Muzan. Sementara ketika Muzan mati ia dan seluruh iblisnya akan musnah dan tidak akan ada pewaris dari perasaan Muzan.

Setelah mendengar pernyataan ubuyashiki kecemasan muncul dari dalam diri Muzan. Karena dari pernyataan ubuyashiki itu ia sadar bahwa yang telah ia lakukan selama ini salah, karena itu ia menunjukkan wajah shock dan kaget. Rasa cemasnya itu membuat id memunculkan keinginan untuk menghilangkan sumber kecemasan tersebut, yaitu dengan menolak pernyataan Ubuyashiki. Namun pernyataan yang disampaikan ubuyashiki juga membuat ego muzan menekan keinginannya yang menolak pernyataan tersebut. Jadi terjadi konflik batin dalam diri muzan antara keinginan id yg ingin menolak pernyataan Ubuyashiki dengan tekanan dari ego untuk membenarkan pernyataan tersebut.

Akhirnya Muzan memutuskan untuk menentang pernyataan Ubuyashiki. Perasaan mengganggu yang ia alami sepeti rasa takut, cemas, dan marah membuat id memunculkan keinginan untuk membunuh Ubuyashiki, agar perasaan mengganggu itu hilang. Seperti yang diceritakan pada chapter 201, sebelum menjadi iblis ia selalu berada di dekat kematian, rasa cemas dan takutnya membuat ia menjadi sangat ingin menjauhi kematian dan menjadi makhluk abadi yang tidak akan pernah hancur atau berakhir. Karena itu meskipun pernyataan dari Ubyashiki Kagaya benar, ia tetap ingin menentangnya.

3) Konflik Batin Dipicu Oleh Kebimbangan Antara Ingin Menyerah Dengan Hidupnya Atau Berusaha Memperjuangkan Hidupnya

Muzan mengalami konflik batin ketika ia berada diambang kematian yang disebabkan oleh pertentangan antara keinginan idnya. Sejak lahir Muzan selalu berjuang untuk terus hidup dengan tubuh yang lemah. Keadaannya yang selama bertahun-tahun selalu dekat dengan kematian, membuatnya bertekad kuat untuk memiliki tubuh yang kuat, abadi, dan tidak akan pernah hancur. Namun selama seribu tahun ia kesulitan mewujudkan keinginannya, dan pada akhirnya ia dikalahkan oleh pasukan pemburu iblis, sehingga ia tidak bisa mewujudkan keinginannya. Hal tersebut memberikan kesedihan pada diri Muzan bahwa usahanya sia-sia, dan berpikir hidupnya akan benar-benar berakhir.

Konflik batin yang dialami Muzan masih berkaitan dengan pernyataan Ubuyashiki tentang keabadian. Muzan ingin terus berusaha memperjuangkan hidupnya, agar segala usaha yang selama ini ia perjuangkan tidak sia-sia, namun di sisi lain rasa sedih akan perjuangannya yang sia-sia membuat ia ingin menyerah akan hidupnya dan membiarkan dirinya kalah. Tanjiro yang pada saat itu berada dihadapan Muzan, didukung oleh situasi sekitar yang hanya ada mereka berdua, hal tersebut membuat Muzan akhirnya memutuskan untuk terus mempertahankan hidupnya melalui Tanjiro dengan cara mewariskan darahnya kepada Tanjiro. Jika Tanjiro berhasil menerima darahnya dan bertahan di bawah sinar matahari, Muzan berharap Tanjiro akan menjadi iblis terkuat yang dapat mewujudkan keinginannya. 


\section{Kesimpulan dan Saran}

Konfilk batin yang dialami oleh tokoh Muzan meliputi kebimbang terhadap tujuannya, menolak atau membenarkan suatu pernyataan, dan antara ingin menyerah dengan hidupnya atau berusaha memperjuangkan hidupnya. Secara keseluruhan permasalahan yang dialami tokoh Muzan dikarenakan adanya pertentangan antara id dengan ego-nya. Adapun faktor lain adalah karena lemahnya super ego Muzan, sehingga selama ia mengalami konflik batin super egonya tidak mampu menekan keinginan dari id maupun tindakan dari ego dengan nilai-nilai moral. Keputusan-keputusan yang diambil Muzan setelah mengalami konflik batin dan juga karena faktor dari super ego yang lemah, membuat Muzan memiliki karakter yang kejam di dalam manga Kimetsu no Yaiba. la menjadi karakter yang akan melakukan apa saja demi mewujudkan keinginannya, bahkan melakukan tindakan keji sekalipun seperti memakan manusia, membunuh manusia, dan mengubah manusia menjadi iblis.

Untuk penelitian selanjutnya diharapkan dapat menganalisis lebih dalam lagi terkait konflik batin yang dialami Muzan, tidak hanya sebatas konflik batin yang dialaminya tetapi juga bagaimana karakteristik dari tokoh Muzan di dalam manga Kimetsu no Yaiba.

\section{Daftar Pustaka}

Andri \& Dewi, Y. 2007. Teori Kecemasan Berdasarkan Psikoanalisis Klasik Dan Berbagai Mekanisme Pertahanan Terhadap Kecemasan. Maj Kedokt Indon, Vol. 57, No. 7, hal. 233-238.

Dewi, M.C, dkk. 2019. Konflik Batin Tokoh Utama Dalam Novel Nyonya Jetset Karya Alberthiene Endah. Jurnal Penelitian Pendidikan Bahasa dan Sastra". Vol. 4, No. 1, hal. $422-428$. 